\title{
Concepto de Formación Geográfica: teoría y método
}

\author{
Vicente Di Cione ${ }^{1}$ \\ Universidad de Buenos Aires \\ @ [ vdicione@yahoo.com ]
}

RECIBIDO 19-06-2021

ACEPTADO 09-08-2021

Cita sugerida: Di Cione, V. (2021). Concepto de Formación Geográfica: teoría y método. Revista Huellas, Volumen 25, № 2, Instituto de Geografía, EdUNLPam: Santa Rosa. Recuperado a partir de: http://cerac.unlpam.edu.ar/index. php/huellas

DOI: http://dx.doi.org/10.19137/huellas-2021-2520

\begin{abstract}
Resumen
Se postula el concepto formación geográfica como necesaria superación teórica y metodológica del concepto de espacio geográfico para designar y abordar los objetos y problemas de la geografía, a los fines de responder simultáneamente a las demandas epistemológicas y prácticas, entre ellas las implicadas en los procesos de enseñanza.
\end{abstract}

Palabras clave: Formación geográfica; Formación social; Geohistoricidad; Dialéctica territorial; Geografía crítica

\section{Concept of Geographical Formation: theory and method}

\begin{abstract}
The concept of geographical formation is postulated as a necessary theoretical and methodological improvement of the concept of geographical space, to describe and address the objects and problems of geography, in order to simultaneously respond to epistemological and practical demands, including those involved in teaching processes.
\end{abstract}

Keywords: Geographic formation; Social training; Geohistoricity; Territorial dialectic; Critical Geography

\section{Conceito de Formação Geográfica: Teoria e método}

\section{Resumo}

Postula-se o conceito de formação geográfica como necessária superação teórica e metodológica do conceito espaço geográfico para designar e abordar os ob- 
jetos e problemas da geografia com a finalidade de responder simultaneamente às demandas epistemológicas e práticas, dentre elas aquelas involucradas nos processos de ensino.

Palavras-chave: Formação Geográfica; Formação Social; Geo-história; Dialética Territorial; Geografia crítica

\section{Presentación}

El texto pretende fundamentar y caracterizar la noción teórica y metodológica de formación geográfica, extrañamente inexistente en el corpus conceptual de la geografía, con el propósito de complementar y superar las notorias dificultades comprensivas y limitaciones operacionales de las nociones ampliamente difundidas de espacio y espacio geográfico para referirse al universo temático de la disciplina. La expresión formación geográfica, veremos, es aplicable a un conjunto amplio de problemas, objetos, procesos y formas de la superficie de la Tierra, la cual es la fuente de inspiración fundacional y del permanente desarrollo de la disciplina. Por tal motivo, formación geográfica constituye a la vez una alternativa de unificación teórica y metodológica superadora de la notoria fragmentación conceptual del conjunto de objetos propuestos en su larga tradición disciplinaria: lugar, paisaje, región, territorio, corema, geoforma, geosistema y, los más recientes, formación socioespacial y formación espacial.

La noción de espacio geográfico respondió a exigencias neokantianas del positivismo generalizado en la etapa de modernización disciplinaria decimonónica, para hacer frente, entre otros aspectos, a la ausencia de un sustantivo apropiado que pudiera sintetizar el campo temático propio de la geografía. (Valcárcel, 2000; Capel, 1981; Gómez Mendoza, 1982)2.

El análisis riguroso de los usos de la noción de espacio geográfico, deja entrever, con mayor o menor explicitación, que denota y connota concretamente la superficie terrestre. La constatación alcanza igualmente a la noción de producción del espacio de Henri Lefebvre (2013). Todos sus ejemplos corresponden a lugares de la superficie de la Tierra ${ }^{3}$.

La noción de formación geográfica, a modo de definición preliminar, denota la multiplicidad de formas y procesos de formación de la superficie de la Tierra (geoformas) que requieren identificarse y caracterizar para 
responder científica y prácticamente a las necesidades civiles, políticas y estatales de las sociedades. Dentro del conjunto de necesidades, ocupa un lugar destacado la educación territorial y ambiental.

La identificación y comprensión de la diversidad de necesidades sociales es fundamental para identificar, demarcar y caracterizar la diversidad de formaciones geográficas. La definición de los requerimientos sociales, de los destinatarios/usuarios, es la primera condición para posibilitar la identificación de las formaciones geográficas, el acotamiento de la escala analítica (variables e indicadores) y la difícil demarcación de la extensión espacial escalar".

La noción de formación geográfica es necesaria para superar frecuentes obstáculos epistemológicos y, a la postre, prácticos, derivados de la experiencia básica de los temas reales que se abordan, sesgados, con menor o mayor intensidad por el sesgo espacial, propenso a reducir las investigaciones geográficas a la geometría de su universo temático. La filosofía y la ciencia se ocuparon largamente de ambos obstáculos en el proceso de lo que Gastón Bachelard denominó Formación del espíritu científico (Bachelard, 1972) ${ }^{5}$.

Seguidamente desarrollaremos algunos aspectos fundamentales de la noción de formación geográfica: la necesidad de recuperar la superficie de la Tierra como campo temático tradicional de la construcción disciplinaria; los momentos analíticos y operacionales básicos de la formación geográfica, reunidos en lo que proponemos denominar Aleph teórico y metodológico general; la importancia de la praxis crítica; las nociones de geograficidad e historicidad como motor de las transformaciones geográficas; la distinción entre nexos dialécticos funcionales y nexos dialécticos contradictorios; el fetichismo geográfico que por lo general opera contrariando las expectativas de las intervenciones; la caracterización de las capas geofísicas de la superficie terrestre; la identificación y caracterización sintética de las instancias/momentos analíticos de las formaciones geográficas atendiendo la interdependencia de las ciencias de la tierra y las ciencias sociales y, por último, pero no en último lugar, la centralidad mediadora y determinante de los procesos de territorialización, para los cuales proponemos la noción de formación territorial.

\section{La superficie terrestre: tradición y renovación superadora}

La adopción de la noción espacio geográfico como objeto disciplinario, produjo un alejamiento del universo empírico que fundamentó y sostuvo su origen desde épocas fundacionales: la superficie de la Tierra. Creemos que es imprescindible recuperar de manera renovada la centralidad que ocupó en la larga tradición disciplinaria. 
La superficie de la Tierra, el suelo, es el principio de todo: el mundo. Es el ámbito en y a partir del cual el hombre es naturaleza y la naturaleza es hombre. Es el lugar de lugares, luego lugar dentro del universo y el universo hecho lugar y lugares.

La centralidad del de la superficie terrestre, como lugar del origen, génesis de la vida en general y de la social en particular, es destacada por muchos autores provenientes de disciplinas muy diversas. Correspondió a las narrativas históricas fundacionales la preocupación por comprender los nexos entre los procesos culturales, políticos y económicos y el carácter geográfico de la naturaleza. La preocupación siempre estuvo presente hasta la actualidad 6 .

El reconocimiento más importante de la superficie terrestre es, desde muchos puntos de vista el de la mayoría de la gente que la habita, trabaja, goza y, con frecuencia, la sufre en los ambientes de los lugares donde transcurren sus vidas cotidianas. Los usos, a menudo incorrectos, de la expresión espacio geográfico, además de los malestares epistemológicos, ha producido un efecto de extrañamiento de la percepción de la gente de la importancia vital del conocimiento geográfico. Son muchas las anécdotas sobre el extrañamiento de la geografía.

Henri Lefebvre, en diversos textos, ha resaltado la importancia de los lugares de la superficie terrestre en la producción y reproducción de la vida cotidiana y la historia social. Sin embargo, muchos geógrafos hicieron lecturas kantianas de la expresión espacio geográfico, sin advertir que fue un recurso para connotar la multiplicidad de lugares y formas de la superficie terrestre ${ }^{7}$.

En perspectiva filosófica, la superficie terrestre es el origen fenomenológico y la fuente de desarrollo del concepto crucial de realidad, en tanto exterioridad de la consciencia y fuente de recursos locacionales y materiales, la madre-tierra, la cual se vive, percibe y representa a partir de la racionalización de las experiencias básicas. De las experiencias y la necesidad de nombrarlas, describirlas, explicarlas y comprenderlas se desarrolla en simultáneo el lenguaje simbólico y todas las formas de representación de la naturaleza: mágicas, religiosas, estéticas, científicas y filosóficas.

La disciplina necesariamente tiene que ser re-plantada, re-enraizada y re-arraigada en el ámbito real del cual la fue alejando las conceptualizaciones y usos del espacio geográfico, con la diversidad de formas implícitas y explicitas del espacialismo de ciertos paradigmas académicos. La superficie terrestre es el lugar de partida concreto y, a la vez, el lugar de retorno, el fin, del desarrollo de saberes, habilidades prácticas y, en general, de la praxis social. La noción de formación geográfica se inscribe en esa dirección de retorno. 


\section{El Aleph teórico y metodológico general: realidad, praxis y dialéctica}

En este apartado desarrollaremos una primera aproximación a la construcción de la noción de formación geográfica, mediante la presentación de aspectos teóricos y metodológicos generales que pueden aplicarse a un conjunto vasto de objetos y problemas que solemos considerar formando parte de la realidad.

En la Figura $N^{\circ} 1$ : Aleph teórico y metodológico general, se mapea los principales momentos conceptuales necesarios para caracterizar la estructura básica de la formación geográfica, mediante la cual es posible orientar la disciplina en las claves del quehacer crítico, apelando a dos aspectos claves: la praxis y la dialéctica de la realidad.

Figura $\mathbf{N}^{\circledR} 1$. Aleph teórico metodológico

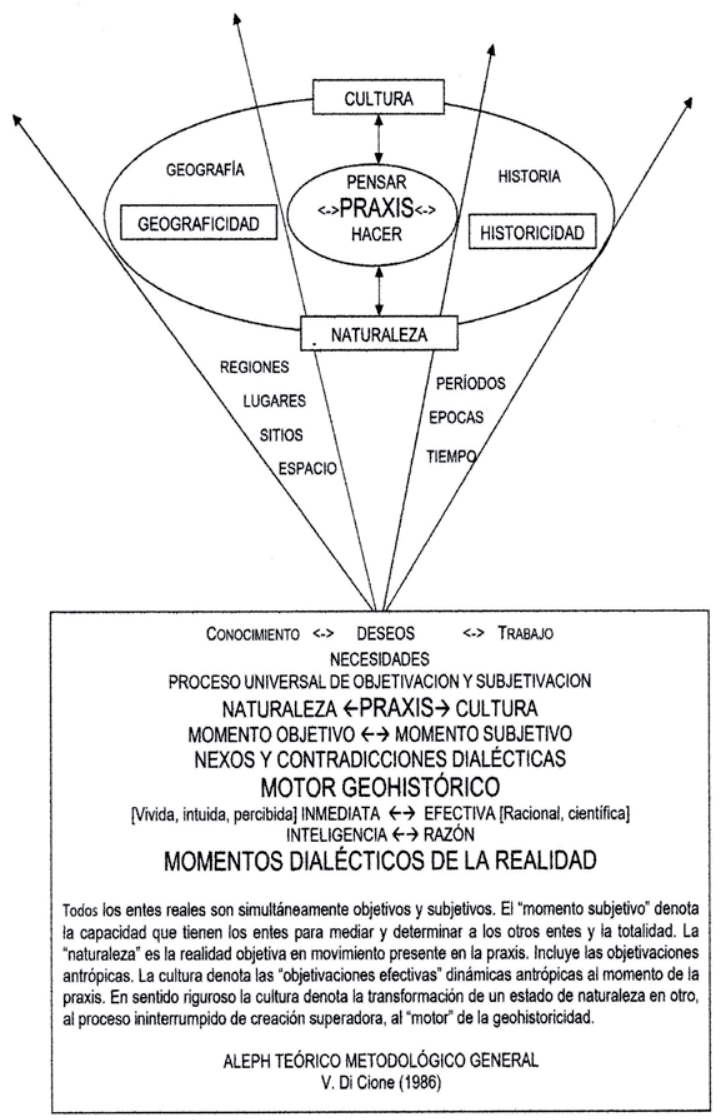

Fuente: elaboración propia 
El Aleph posibilita, además, el trazado de múltiples itinerarios de construcción de las formaciones geográficas en el vasto horizonte de los desarrollos intra, inter y trans objetales y disciplinarios.

La primera postulación que surge del Aleph consiste en aceptar que el objeto de la geografía es la unidad dialéctica espacio-temporal, geográfica e histórica, de la naturaleza y la cultura. La unidad está suficientemente corroborada por la historia y el conjunto de prácticas disciplinarias actuales, documentadas en libros e informes de investigaciones de estudios de casos y notoriamente menos en los textos de epistemología. La postulación implica asumir que el espacio geográfico, en sentido riguroso, constituye solo una forma o momento de la combinación espacio-temporal de la naturaleza y la cultura.

El campo temático, por consiguiente, se despliega sobre los cuatro cuadrantes y sectores del Aleph. El despliegue no implica que el campo temático está constituido por la totalidad. Solo expresa los itinerarios y sentidos posibles de los procesos disciplinarios en términos de las orientaciones analíticas y totalizadoras de la construcción de las formaciones geográficas involucradas, en perspectivas intra, inter y transobjetales y disciplinarias.

Los frecuentes giros epistemológicos de la disciplina se describen, explican y comprenden a partir de la disposición y orientaciones posibles de la geografía dentro del Aleph, el cual también posibilita comprender los giros que tienen origen en los otros cuadrantes orientados hacia la geografía. Es el caso de las producciones geográficas, harto frecuentes, realizadas por los profesionales de las ciencias de la tierra (ciencias de la naturaleza), las ciencias sociales (historia y ciencias de la cultura o ciencias humanas).

La noción y estructura básica, universal, de lo que se considera realidad geográfica condensada en el Aleph, está relativamente soslayada en los textos de epistemología de la disciplina, lo cual dificulta las posibles relaciones dentro del vasto campo de disciplinas empíricas. La conceptualización crítica de la realidad, a pesar de su importancia, se la considera cosa obvia.

El Aleph puede considerarse como un esquema de una macro teoría de la realidad de alcance universal, razón por la cual es preformativa de todos los objetos y procesos empíricos disciplinarios. La realidad lo envuelve todo. La figura $\mathrm{N}^{\circ} 1$ del cono invertido, es congruente con los procesos de complejización analítica de los objetos y procesos empíricos que comienzan a partir de ciertos vórtices de atención intelectual y prácticos condensados en ideas difusas inmediatas derivadas de experiencias perceptivas o deducidas e inducidas en los límites de los marcos teóricos y metodológicos existentes, a modo de hipótesis ${ }^{8}$ de trabajo ${ }^{9}$. 
Hegel, en posición crítica con Kant, consideró que aquello que denominamos realidad, no es algo que preexiste a la experiencia humana, sino el resultado de un complejo proceso de experimentación y construcción racional mediado por palabras-conceptos. Atendiendo a las formas de la experimentación y de construcción conceptual, propuso distinguir la realidad inmediata y la realidad efectiva. Ambas son el resultado de la praxis social.

La praxis denota la realización de prácticas humanas mediadas y reguladas cultural y racionalmente, orientadas a satisfacer necesidades sociales y deseos personales mediante uso de saberes y habilidades, con menor o mayor grado de recursos técnicos: habilidades adquiridas, instrumentos y saberes, entre ellos las teorías científicas y filosóficas. Para Hegel el mayor grado de construcción de la realidad efectiva implica un mayor grado de racionalidad científica y filosófica.

La realidad inmediata es la que se da fundamentalmente en la experiencia sensorial de la materialidad y con habilidades, recursos y conocimientos relativamente naturalizados (a-críticos) en el lenguaje y formas diversas de representación. No es posible la construcción de la realidad efectiva, la realidad totalizada conceptualmente, sin el incesante retorno a la realidad inmediata de la experiencia. La propuesta condensó en la celebrada expresión hegeliana todo lo real es racional y todo lo racional es real.

El Aleph teórico y metodológico de la Figura $N^{0} 1$ es una simplificación didáctica orientada a explicitar los aspectos y momentos analíticos básicos y generales de la realidad efectiva resultante de la evolución histórica y geográfica de la praxis científica y filosófica. Cada término de la figura expresa diferentes momentos, rostros, de la realidad como totalidad. Alcanza a las características esenciales de la formación geográfica y de todas las formaciones materiales e ideales, tales como los conceptos de formación geológica, formación social, formación económica, formación discursiva y muchas otras ${ }^{10}$. Las formaciones no son cosas, no son figurables. En la disciplina en una patología epistemológica cierto sesgo de reemplazar los conceptos con imágenes.

El término formación, utilizado con harta frecuencia, amerita algunas aclaraciones. En término denota a la dualidad formación como proceso y formación como producto del proceso. Todas las formaciones son el producto de procesos de producción. El proceso de producción consiste en un conjunto de actividades materiales y mentales (ideales) reguladas por los marcos teóricos y metodológicos, los que a su vez son resultado de complejos procesos sociales de producción. Los marcos teóricos y metodológicos son, por consiguiente, formaciones epistemológicas. La expresión es pertinente por cuando en las prácticas disciplinarias es frecuente la convergencia de diferentes modos de producción y reproducción científica. 
La figura del cono invertido ${ }^{11}$ representa la espiral dialéctica de ascenso de la realidad inmediata indiferenciada a la realidad efectiva reconstruida a partir del paulatino discernimiento de momentos analíticos resultantes de la praxis. Representa la evolución del círculo concreto-abstracto-concreto $^{12}$. En rigor la evolución es mejor expresada como espiral ${ }^{13}$.

La naturaleza denota el conjunto de recursos materiales e ideales dados (disponibles) a la apropiación de la praxis. El desarrollo histórico y sicogenético de la praxis revela paulatinamente la necesidad de la distinción entre primera naturaleza y segunda naturaleza La cultura, en su forma inmediata, denota la naturaleza transformada antrópicamente. Sin embargo, durante el proceso, la cultura se naturaliza, se presentará como un nuevo estado natural, dando lugar a una fase superior de la naturaleza dada al comienzo del ciclo: la segunda naturaleza. El pasar de un cierto estado de naturaleza a otro estado superior, denota rigurosamente el término cultura. Cultura es sinónimo de proceso de superación del estado de naturaleza que es punto de partida de la praxis. La superación cultural consistente en desechar lo que no sirve o se demuestra falso y preservar de manera diferente y superior en un nuevo estado de la cultura aquello que es útil y verdadero. El nuevo estado de la cultura es resultado de un acto de creación a partir de los materiales y recursos de valorización de cierto estado de naturaleza. El ciclo se cierra en un nuevo estadio de la segunda naturaleza ${ }^{14}$.

El cono invertido representa un continuo proceso de deconstrución y superación de la unidad espaciotemporal de la unidad de los momentos naturaleza y cultura. Cada estadio o etapa superior del conjunto implica una ampliación de los momentos analíticos de la capa precedente, la cual se expresa en redefiniciones intra, inter y transobjetales de los momentos que son constitutivos, a su vez, de los procesos de desarrollos intra, inter y transobjetales (Piaget-García, 1982). La apertura analítica de la cultura y la naturaleza es el motor de recomposición del complejo campo de división disciplinaria del trabajo intelectual. Por lo general se traducen en un entramado de contradicciones del campo científico institucional, en los que cada disciplina disputa la apropiación de los nuevos capitales simbólicos (Bourdieu, 1966, 1988) ${ }^{15}$.

Uno de los problemas fundamentales de la geografía es el significado del tiempo y las formas de temporalizar la diversidad de formaciones geográficas. Omitimos desarrollar las alternativas posibles. Solo distinguiremos las dos formas básicas: la estrictamente cronológica, las típicas series fechadas, y las formas que suman los procedimientos de fechado y la identificación de los cambios cuantitativos y estructurales. Las últimas son las que adoptó Marx sobre el desarrollo de las formaciones sociales en base a la sucesión de fases y etapas de las transformaciones de los mo- 
dos de producción. A partir de la década de los 60' fueron utilizadas por los abordajes histórico-estructurales desarrollados por los historiadores y economistas.

En geografía es ampliamente conocida la periodización histórico-estructural de la formación social de Argentina y las regiones realizadas por los historiadores en base a la sucesión de modos de producción: precolonial, colonial, agroexportadora, sustitutiva de importaciones y neoliberal en curso (Rofman y Romero, 1973; Sunkel y Paz, 1970).

\section{Los momentos objetivos y subjetivos de las formaciones geográficas}

En el esquema del Aleph resaltamos en el cuadro del vórtice inferior del cono la dialéctica entre el momento objetivo y el momento subjetivo. La distinción es fundamental para abordar los procesos reales de las transformaciones geográficas materiales y de las construcciones intelectuales (Di Cione, 1999, pág. 61 a 70).

Lamentablemente el positivismo y el cientificismo, a partir del kantismo filosófico y epistemológico, han contribuido a divorciar la unidad sujeto-objeto, con lo cual se difumina el abordaje de los agentes y agencias que operan de manera interdependiente, desigual, combinada y, con frecuencia, contradictoria, en la apropiación, uso y transformación de la realidad geográfica.

Los momentos objetivos y subjetivos están presente en todas las partes y procesos de la realidad. No constituyen dos sistemas relativamente autónomos, tal como lo propuso, además de otros, Milton Santos (2000). Por tal motivo, en tanto dos rostros de todos los objetos y fenómenos reales discernibles, los sujetos y los objetos ameritan la osadía de proponer dos neologismos: sujetoobjeto o objetosujeto, indistintamente. Ambos términos son aplicables a todos los agentes y agencias que, como veremos, territorializan la superficie terrestre.

El momento subjetivo denota a la capacidad organizativa de todas las cosas reales. Todas las cosas reales son vórtices organizativos, con o sin conciencia y voluntad de organización. Es una cualidad inherente al simple hecho de existir y estar en la totalidad del mundo y estar inevitablemente relacionado con todas las partes que lo integran. Todo lo existente, puede decirse, está cargado de subjetividad. Todas las cosas están cargadas objetivamente, valga la expresión, de subjetividad: por el origen que las ha producido y por los comportamientos que, debido a su naturaleza, a su forma, obliga necesariamente a todas las cosas con las cuales se vincula ${ }^{16}$.

No hay cosas y personas en la Tierra y el Mundo que carezca de capacidad mediadora y de determinación sobre el resto que lo rodea y lo constituye. Tampoco hay cosas que formando parte de la Tierra y del Mundo 
puedan tener una existencia objetiva des-articulada de la totalidad de la que forma parte. Todos los entes, incluyendo las cosas, son actantes ${ }^{17}$.

El momento objetivo de la realidad ya lo hemos explicitado: denota el ambiente que rodea a las cosas, ambiente que, tal como lo caracterizamos, no constituye un sistema relativamente autónomo, sino una especie de éter cargado de subjetividad que lo envuelve y penetra a todo lo existente. Las ideas también son objetivas y actantes, en tanto momento de la praxis.

La interdependencia de ambos momentos tiene la enorme capacidad interpretativa y explicativa para negar la unilateralidad de ciertas visiones deterministas e indeterministas y recuperar las mediaciones y determinaciones de todo en clave de relaciones dialécticas, es decir, como resultado posible de los juegos de determinación de todo con todo.

\section{Del espacio-tiempo a la geograficidad, historicidad y geohistoricidad}

En el Aleph el espacio y el tiempo están situados al comienzo del vértice del cono invertido, congruente con las postulaciones de Kant y Hegel, aun cuando su constitución y función difieren.

En los niveles superiores ubicamos la formación de momentos de la espacialidad y la temporalidad: los sitios, lugares, regiones, coremas, geografías y geograficidad, en los cuadrantes del lado espacial, y épocas, períodos, formas diversas de cronologías, historia e historicidad en los cuadrantes correspondientes al tiempo. Dentro de la geograficidad falta ubicar explicitamente a la formación geográfica y dentro de la historicidad a la formación histórica.

En términos dialécticos los diferentes momentos, considerados aislada y formalmente, son conceptos abstractos. Todos los momentos están imbricados por las transformaciones del conjunto. La identificación, caracterización y ensamble dialéctico de los momentos subjetivos y los momentos subjetivos de las realidades geográficas es clave para descubrir lo que proponemos denominar geograficidad, valga la expresión, de la realidad geográfica en general y de la multiplicidad de formaciones geográficas.

El término es usado frecuentemente para designar aquello que hace que los objetos y procesos puedan considerarse geográficos. Los usos habituales denotan las condiciones de sitio y posición de los objetos y procesos. Sin dejar de reconocer la utilidad del término con el significado precedente, se propone utilizarlo para denotar la capacidad que tienen las formaciones geográficas para transformarse superadoramente, es decir, aniquilar lo que no cumple ninguna función o son obstáculos para las territorializaciones de agentes y agencias, preservar lo que sirve, y reconfigurar lo que se preserva con la producción de nuevos aportes. 
Conlleva a la necesidad de sumar otro concepto: los modos de producción y reproducción geográfica de la geograficidad de las formaciones geográficas, de manera similar a los significados y funciones de modos de producción de las formaciones sociales que fuera propuesto por Marx en la Introducción a la crítica de la economía política/1857 (hay muchas ediciones disponibles). El término geograficidad es similar y combina necesariamente con la noción de historicidad propuesto por Heidegger para designar el motor de la historia humana, es decir, la capacidad que tienen las formaciones sociales para transformar y superar incesantemente la sucesión de estados de naturaleza, es decir, la sucesión de estados de la naturalización cultural. La geograficidad y la historicidad son dos momentos de la dialéctica de la realidad. Ambos son expresiones de la dialéctica subjetivo-objetivo y, a la vez, instancias de materialización de los sentidos del espacio y del tiempo, transformados ambos conceptualmente en geografía e historia.

\section{Nexos dialécticos funcionales y nexos dialécticos contradictorios}

Todo se relaciona con todo. Luego todo está mediado y determinado con nexos con cualidades generales y cualidades específicas. Las investigaciones empíricas demandan la dialéctica entre lo universal y lo singular, mediadas por instancias particulares.Los tres momentos entreveran tres escalas teóricas: la teoría general o universal de la realidad, en nuestro caso sintetizada en el Aleph y las teorías concretas o específicas de los objetos y fenómenos reales. Ambos momentos teóricos son mediados por teorías particulares, es decir, teorías que condensan aspectos generales de ámbitos particulares de la realidad. Hay muchos ejemplos: la teoría de los movimientos de placas posibilita teorizar sobre los fenómenos tectónicos específicos, tales como los frecuentes terremotos en Haití, Cuyo, Italia y muchos otros lugares; la teoría urbana posibilita la elaboración de teorías sobre el desarrollo de la infraestructura y equipamiento de áreas específicas; la teoría de la renta del suelo posibilita las teorías de cambios de usos del suelo en áreas rurales y urbanas.

Todas las relaciones cumplen funciones generales comunes: religar las partes en las totalidades de las que forman parte y las partes entre sí. Dentro de la variedad de relaciones involucradas en las investigaciones concretas, es necesario distinguir las relaciones que solo constituyen vínculos dialécticos funcionales y las relaciones que expresan contradicciones subjetivas, es decir, entre sentidos organizacionales contradictorios de las partes.

Bobbio $(1964,1971)$ propuso denominar a las relaciones funcionales nexos dialécticos y a las relaciones contradictorias contradicciones dialécticas. Proponemos reemplazar a ambos con las expresiones nexos dialécticos funcionales y nexos dialécticos contradictorios. Los nexos dialécticos 
funcionales son condición necesaria, aunque no suficiente, para el desarrollo de nexos dialécticos contradictorios. El carácter contradictorio de los nexos dialécticos es el resultado del desencuentro, contradicción, entre los requerimientos productivos y reproductivos de las partes relacionadas de manera desigual y combinada.

La superación de los nexos dialécticos contradictorios puede optar por tres alternativas: afirmación o cambios en las formas de regulación de los nexos, lo cual supone la preservación o cambios puramente cuantitativos de los modos de producción y reproducción dominantes en las formaciones geográficas, cambios estructurales de los modos de producción y el consiguiente pasaje a modos de regulación diferentes o, lisa y llanamente, la supresión de una de las partes por la otra sin operar cambios estructurales del conjunto. Los procesos de concentración y centralización económica son ejemplos de la última alternativa. La primera alternativa es la llevada a cabo por las posturas regulacionistas de los estados social democráticos.

\section{Fetichismo geográfico}

La dualidad de los nexos geográficos, funcionales y contradictorios, y la combinación de los momentos objetivos y subjetivos dan lugar a procesos y objetos que pueden subvertir los sentidos de las praxis, mediante la independencia del control de los productores que le dieron origen e, incluso oponerse a sus requerimientos. La pérdida de control implica que los productos adquieren una existencia objetivasubjetiva relativamente autónoma, la cual puede incluso entrar en contradicción con los productores.

El proceso explica el carácter relativamente fetichista de las actividades antrópicas, derivadas de imposibilidad de regular los alcances de la multiplicidad de formas de territorialización mediante prácticas de regulación del carácter social de los procesos productivos y el carácter privado de las apropiaciones territoriales. El fetichismo geográfico es similar al fetichismo de la mercancía que desarrolló Marx en El Capital. Ningún sujetoobjeto, ningún productor, tiene capacidad para someter a voluntad los comportamientos del conjunto de sujetosobjetos, conjunto de productores, de la totalidad de la cual necesariamente forman parte. La naturaleza presente en las formaciones geográficas reales responde a su propia lógica, la cual es relativamente impredecible (sistema abierto) (Margulis, 2005; Mils, 2007).

\section{Momentos e instancias analíticas de la formación geográfica}

Los cuadros $\mathrm{N}^{\circ} 1$ y $\mathrm{N}^{\circ} 2$ sintetizan lo que podemos denominar estratigrafía de las formaciones geográficas. El Cuadro $N^{\circ} 1$ resume el conjunto de estratos y capas fundamentales de la Tierra realizado sobre la vertical 
con origen en el centro. El perfil vertical es reproducible en todos los puntos de la superficie terrestre, aun cuando las características concretas varíen cualitativa y cuantitativamente en todos los puntos de los desplazamientos posibles y los puntos de las áreas próximas. Los valores cualitativos y cuantitativos reales son el resultado de investigaciones de casos.

En las formaciones geográficas usuales, el estrato fundamental corresponde con la antroposfera o, con mayor rigor, el hipervolumen de la ecúmene. Ambos, globalización mediante, se superponen. No hay consensos sobre el espesor de ambos estratos. La especificación de los espesores y la escala analítica de contenidos dependerán de los propósitos de identificación y aplicación de las formaciones geográficas. Son muy diferentes los recortes si se procura encarar una planta de aprovechamiento de la energía solar mediante paneles fotoeléctricos, estimar la productividad de un viñedo, fijar corredores de aeronavegación, realizar predicciones climáticas, estimar la productividad de biomasa de un ecosistema o calcular la recurrencia y riesgos de tormentas y lluvias torrenciales.

Cuadro $\mathrm{N}^{\circ}$ 1: Estratigrafía geofísica de la formación geográfica.

\begin{tabular}{|c|}
\hline $\begin{array}{c}\text { Antropósfera, Ecúmene [espesor } 12 \mathrm{~km}] \\
\text { Capa de la superficie terrestre con usos antrópicos } \\
\text { Superficie terrestre usada para asentamientos urbanos, rurales, mineros, navegación } \\
\text { aérea y marítima } \\
\text { FORMACIONES TERRITORIALES ANTRÓPICAS }\end{array}$ \\
\hline Tropósfera [0-13 km altura] Determina el clima/tiempo \\
\hline $\begin{array}{l}\text { Biósfera (envoltura viva, Ecosistema Global [ Espesor medio } 20 \mathrm{~km} \text { ] } \\
\text { Capa fotosintética superficial ( } 50 \% \text { continental y } 50 \% \text { oceánica) } \\
\text { Capa quimiosintética }\end{array}$ \\
\hline $\begin{array}{l}\text { Materia orgánica, cuerpos orgánicos } \\
\text { FORMACIONES TERRITORIALES ORGÁNICAS }\end{array}$ \\
\hline Materia inorgánica y cuerpos inorgánicos litosféricos / Formaciones geológicas \\
\hline Momento físico y químico \\
\hline $\begin{array}{l}\text { [Homósfera [0-100 km ] / Heterósfera [100-10000km] } \\
\text { Superficie terrestre / Tropósfera / Stratósfera / Mesósfera / Exósfera / }\end{array}$ \\
\hline $\begin{array}{c}\text { Litósfera [0-40 km] / Astenósfera [ 40-700 km] /Mesósfera [ 700-2900 km ] Profundidad } \\
\text { máxima alcanzada } 12.2 \text { km (Península de Kola) } \\
\text { Corteza (piel del planeta ) [0-40 km] / Manto (motor de la corteza) / Mesósfera o Manto } \\
\text { profundo [40-2900 km] / Núcleo externo [ 2900-4980 km] / Núcleo interno [5120-6371 km] }\end{array}$ \\
\hline
\end{tabular}

Fuente: Elaboración propia. 
El Cuadro $N^{\circ} 1$ explicita las capas/estratos de la Tierra identificados y caracterizados sistemáticamente por el campo de las ciencias de la tierra y la geografía física. En el estrato antrópico, correspondiente a la superficie de la Tierra y coincidente en la actualidad con el hipervolumen de la ecúmene globalizado, los intercambios horizontales y verticales son relativamente intensos, dependiendo de muchos factores, tematizados intra, inter transdisciplinariamente por la geología (en menor grado), geomorfología, biología, ecología, climatología, edafología, hidrología, oceanografía, climatología, la geografía, el urbanismo y la economía política.

El concepto teórico y metodológico de formación geográfica, es inexistente en las ciencias de la tierra, incluyendo la geografía física. La geología desarrolló el concepto de formación geológica, confinándolo a la identificación y caracterización de unidades litoestratigráficas. Para otras unidades de diferentes escalas y constitución utiliza una amplia variedad de términos formalmente definidos en sus diversos nomencladores.

Los intercambios verticales y horizontales de las ciencias de la tierra son encarados en términos físico-químicos y orgánicos en el sentido amplio. Las formaciones geográficas son abordadas focalizando los nexos dialécticos que operan en su estructuración. La estructura denota los momentos definitorios para la identificación de unidades particulares de la superficie de la Tierra, caracterizada por su función regulatoria general de las totalidades identificadas y las potencialidades de transformación, con mayor o menor atención en la preservación o transformación intensa de las determinaciones estructurales.

El concepto de formaciones territoriales orgánicas denota los procesos de territorialización que caracterizan la competencia entre los organismos vivos y las formaciones biológicas del biotopo. Hay muchos ejemplos. Destacamos, por su profundo impacto, la competencia entre especies autóctonas y especies alóctonas, las últimas resultantes de prácticas antrópicas culturales orientadas a satisfacer una gran variedad de necesidades: alimentación, incremento de rentas diferenciales, ornamentales, etc.

Podría extenderse, quizás abusivamente, a ciertos procesos geomorfológicos derivados de prácticas mineras y agrícolas de escala. La gran minería a cielo abierto es un ejemplo notable. Las actividades agrícolas extensivas o intensivas, con impactos fuertes en la resiliencia de los ecosistemas, son ejemplos destacados. Ambos son interpelados y criticados desde un par de décadas por variados movimientos ecológicos y ambientalistas, basándose en el controvertido concepto de extractivismo.

El Cuadro $N^{\circ} 2$ explicita los aspectos y momentos de las formaciones geográficas en clave de la geografía humana, la ecología social, la economía política, el ordenamiento territorial y ambiental, la geografía política, la etnología y todos los campos problemáticos que implican centralmente 
las formaciones sociales y agentes que territorializan la superficie de la Tierra. En estas formaciones de la superficie de la Tierra, sean puntuales, lineales 0 areales, los atributos cualitativos y cuantitativos también deberán determinarse mediante observaciones y mediciones singulares.

Cuadro $\mathbf{N}^{\circ}$ 2. Instancias y momentos naturales y culturales de la formación geográfica

\begin{tabular}{|c|c|}
\hline 1 & $\begin{array}{c}\text { INSTANCIA IDEOLÓGICA (Weltanschauung) SIMBÓLICA / SENTIDOS } \\
\text { AXIOLÓGICOS } \\
\text { FORMACIONES TERRITORIALES SIMBÓLICAS }\end{array}$ \\
\hline 2 & $\begin{array}{c}\text { ESTADO (SENTIDO AMPLIO) (Hegemonía acorazada de coacción) } \\
\text { COMPROMISOS DE ADHESIONES INTERNACIONALES } \\
\text { DISTRIBUCIÓN TERRITORITORIAL DE PODERES } \\
\text { Formaciones estatales } \\
\text { ESTATAL: UNITARIO / FEDERAL } \\
\text { AUTONOMÍAS SUBALTERNAS: Regiones, Provincias, Departamentos, Partidos/ } \\
\text { Municipios, Comunas } \\
\text { FORMACIONES TERRITORIALES ESTATALES }\end{array}$ \\
\hline 3 & $\begin{array}{c}\text { INSTANCIA JURÍDICA } \\
\text { Leyes, decretos, ordenanzas y normas jurídicas generales de regulación de } \\
\text { actividades } \\
\text { Convenios y acuerdos internacionales }\end{array}$ \\
\hline 4 & $\begin{array}{r}\text { SOCIEDAD POLITICA (Formaciones de disputación y articulación sociedad civil } \\
\text {-sociedad política - estado) } \\
\text { Bloques históricos (alianzas), Partidos políticos y organizaciones informales de } \\
\text { acción política } \\
\text { Organizaciones de la sociedad civil (Corporaciones empresariales, sectoriales, } \\
\text { gremiales y locales } \\
\text { FORMACIONES TERRITORIALES POLITICAS }\end{array}$ \\
\hline 5 & $\begin{array}{l}\text { SOCIEDAD CIVIL (Formaciones sociales privadas) Personas y organizaciones de } \\
\text { derecho } \\
\text { FORMACIONES TERRITORIALES CIVILES }\end{array}$ \\
\hline & $\uparrow$ SUPRAESTRUCTURA $\leftarrow \rightarrow$ INFRAESTRUCTURA $\downarrow$ \\
\hline 6 & $\begin{array}{c}\text { ECONOMÍA POLITICA } \\
\text { Actividades, relaciones de PRODUCCIÓN-CONSUMO-DISTRIBUCIÓN-CAMBIO- } \\
\text { CIRCULACIÓN de bienes y servicios } \\
\text { Formas de producción y distribución del plusvalor social } \\
\text { Políticas de desarrollo territorial - políticas territorializadas de ingresos y egresos } \\
\text { públicos } \\
\text { FORMACIONES TERRITORIALES ECONÓMICAS }\end{array}$ \\
\hline
\end{tabular}




\begin{tabular}{|c|c|}
\hline 7 & $\begin{array}{c}\text { MODOS DE PRODUCCIÓN Y REPRODUCCIÓN SOCIAL CAPITALISTAS Y NO } \\
\text { CAPITALISTAS, DOMINANTES Y SUBALTERNOS (Según formaciones geográficas) } \\
\text { RELACIONES SOCIALES - RELACIONES DE PRODUCCIÓN } \\
\text { Formas de propiedad y apropiación de la naturaleza y los medios de producción } \\
\text { Procesos de clasificación (dialéctica de formación de clases sociales) }\end{array}$ \\
\hline 8 & $\begin{array}{c}\text { FUERZAS SOCIALES - FUERZAS DE PRODUCCIÓN } \\
\text { Población - Aspectos demográficos - Fuerza de trabajo (Capitalista y no-capitalista) }\end{array}$ \\
\hline \multirow[t]{2}{*}{9} & $\begin{array}{c}\text { MEDIOS DE PRODUCCIÓN y REPRODUCCIÓN SOCIAL } \\
\text { Medios de trabajo - Medios de vida - Suelo como locus standi } \\
\text { Conocimientos prácticos - conocimientos y artefactos tecnológicos } \\
\text { Objetos de trabajo: naturaleza como objeto universal del trabajo, suelo agrícola, } \\
\text { litósfera y atmósfera como fuente de recursos mineros metalíferos, no metalíferos, } \\
\text { termales, energéticos }\end{array}$ \\
\hline & $\uparrow$ INFRAESTRUCTURA NATURAL $\downarrow$ \\
\hline 10 & $\begin{array}{c}\text { SEGUNDA NATURALEZA } \\
\text { Instancia específica de objetivaciones antrópicas } \\
\text { FORMACIONES TERRITORIALES ANTRÓPICAS OBJETIVADAS }\end{array}$ \\
\hline 11 & $\begin{array}{c}\text { PRIMERA NATURALEZA } \\
\text { Instancia específica de procesos naturales sin intervención antrópica } \\
\text { FORMACIONES TERRITORIALES NO ANTRÓPICAS } \\
\text { FORMACIONES GEOLÓGICAS Y GEOMORFOLÓGICAS DE SUPERFICIE } \\
\text { DERIVADAS DE FACTORES ATMOSFÉRICOS Y LITOSFÉRICOS NO AFECTADOS } \\
\text { ANTRÓPICAMENTE }\end{array}$ \\
\hline \multicolumn{2}{|r|}{$\begin{array}{l}\text { ACLARACIONES: La disposición en capas de las instancias o momentos es un recurso } \\
\text { analítico de exposición. Todas son momentos dialécticos formadoras de las formaciones } \\
\text { geográficas reales (concretas) de objetos y relaciones de cualquier escala (puntuales, li- } \\
\text { neales, superficiales o volumétricas (materiales). En las investigaciones empíricas guían } \\
\text { sistemáticamente el análisis. Al final es necesario recuperar con el pensamiento la realidad } \\
\text { efectiva (teórica) mediante la síntesis de los momentos analíticos descubiertos (Dialéctica } \\
\text { de la investigación). }\end{array}$} \\
\hline
\end{tabular}

Fuente: elaboración propia.

Expresado en términos relativamente soslayados desde un tiempo, $\mathrm{El}$ Aleph teórico metodológico general expresa el momento nomotético (teórico) de la formación geográfica, el marco desde el cual se preforman los estudios de caso para recuperar las singularidades idiográficas indispensables a los objetivos de la individualización y caracterización de las formaciones geográficas reales ${ }^{18}$. 
La formación geográfica, a diferencia de formación social, denota la articulación específica de la sociedad con la diversidad de formas y situaciones geográficas de la naturaleza, incluyendo las territorializaciones orgánicas de la biomasa. La articulación se realiza mediante los procesos de territorialización (apropiación y usos) de la geografía real por la multiplicidad de agentes (momento subjetivo) constituidos por sus posiciones de clase y clasificación estructurales funcionales y, casi siempre, contradictorias dentro de las formaciones sociales y las condiciones de sitio y posición geográficas asociadas y determinantes de sus posiciones estructurales. Las posiciones estructurales dentro de la formación social y las posiciones estructurales dentro de las formaciones geográficas, expresan dos momentos dialécticamente interdependientes, mediados, como veremos más adelante, por los factores intervinientes en los procesos culturales y naturales de territorialización.

La necesidad de formación geográfica se fundamenta en la necesidad de articular las instancias que normalmente forman parte de la geografía física, geología y ecología con las instancias específicas de las formaciones sociales 0 , en rigor, formaciones culturales. El lugar y los locales (Giddens, 1995) de la socialización y sociabilidad son instancias mediadoras y determinantes dialécticamente de los procesos de clasificación de los agentes dentro de las formaciones sociales. En gran medida el carácter contradictorio de las posiciones sociales es resultado de las disputas de apropiación y de sentido de los lugares, en tanto el lugar proporciona las condiciones materiales de existencia ${ }^{19}$.

La expresión "reproducción social" del cuadro denota la historicidad tratada precedentemente, en términos de preservación de la estructura o de superación de los límites de transformación de la estructura.

Trasladados a la formación geográfica, es plausible proponer las expresiones reproducción geográfica y geograficidad con las denotaciones que hemos desarrollado anteriormente.

En las formaciones geográficas concretas actuales, al igual que en las formaciones sociales, coexisten diferentes modos de producción económicos y modos de reproducción geográficos. El capitalismo es hegemónico. Sin embargo, hay suficientes investigaciones que demuestran que el capitalismo no puede desarrollarse en todas las formaciones geográficas sin desarrollar al mismo tiempo formas no capitalistas de producción y reproducción.

Los modos de producción no capitalistas no siempre son modos pre capitalistas desplazados por el capitalismo, base de la acumulación originaria o acumulación por desposesión (Harvey) o, mejor, despojo. Son modos de producción que implican, en última instancia, formas de apropiación de plusvalía social generada por relaciones de producción que no suelen 
entrar en el panóptico de la economía política y, a menudo tampoco en el de la geografía humana actual, propensa a ver todo como resultado de las relaciones capitalistas. Son modos de producción no-capitalistas las variadas formas de producción doméstica, orientadas exclusivamente a la subsistencia de las familias.

La producción doméstica no es sinónimo de trabajo de la mujer. Denota el trabajo de mujeres, varones, niñas, niños, ancianas y ancianos, orientado a la subsistencia cotidiana de manera solidaria. Incluye la producción de bienes y servicios cotidianos (alimentación, aseo, vestimenta), no contemplados usualmente en las relaciones de trabajo asalariadas. No menos importantes es la satisfacción de lo que Topalov (1979, 1984) denomina "necesidades disociadas de las relaciones salariales inmediatas". Una de las necesidades más importante es la autoconstrucción de la vivienda, práctica muy difundida en las geografías de Argentina, Latinoamérica y África.

En las geografías señaladas, son importantes una gran cantidad de producción de bienes y servicios muy diversos orientados a los mercados predominantemente informales. En muchas geografías, se destaca la producción de alimentos, destinadas a la propia subsistencia y a mercados informales (ferias) próximos e incluso lejanos, mediados por un complejo sistema de acopio y distribución.

Las geografías urbanas y rurales de los continentes señalados abundan las formas no capitalistas de producción y reproducción. Algunos autores, entre ellos Milton Santos, ubicaron a las formas no capitalistas como constitutivas de circuitos inferiores de las formaciones sociales capitalistas relativamente autónomos y, a menudo, excluidas de los circuitos superiores de las formaciones capitalistas.

Las investigaciones demuestran que los circuitos son dos momentos de un solo circuito dominado por el modo de producción capitalista, unificados por una intrincada capilaridad que requiere ser observada con más minuciosidad para superar la percepción de la realidad inmediata de los paisajes de ciertas formaciones geográficas.

En las geografías rurales la combinación de modos capitalistas y no capitalistas se fueron desarrollando por la expansión de las fronteras territoriales agrarias del capitalismo sobre las formas precapitalistas existentes. Las disputas por la tierra fueron intensas. También fueron intensos los procesos de desestructuración de las economías preexistentes no capitalistas, por medios coercitivos o por las posibilidades que ofrecía el capitalismo de monetarización mercantil mediante su incorporación salarial de la fuerza de trabajo de las poblaciones preexistentes.

A diferencia de la disposición en estratos y capas del Cuadro $N^{0} 1$, relativamente diferenciadas por capas de transición que pueden ser identificadas e incluso medidas, las instancias y momentos del Cuadro $\mathrm{N}^{\circ} 2$ expre- 
san relaciones y aspectos dialécticos que solamente pueden identificarse y caracterizarse penetrando en el entramado de los nexos y contradicciones dialécticas de las formaciones geográficas. Esta necesidad de superar la realidad inmediata y elevarse a la realidad efectiva, exige el concurso del Aleph teórico metodológico sintetizado en la Figura $\mathrm{N}^{0} 1$ y los momentos plasmados en el Cuadro $\mathrm{N}^{\circ} 1$ y el Cuadro $\mathrm{N}^{\circ} 2$.

La imbricación de los momentos implica atender tres aspectos o momentos teóricos y metodológicos fundamentales. El primero consiste en no perder de vista que cualquier parte real de las formaciones, por ejemplo, la estructura específica de una relación de producción, o de una relación social o técnica, implica el concurso de todos los restantes momentos. La perspectiva, la hemos adelantado: cada momento, relación, objeto, proceso o lo que fuera, condensa la totalidad de los momentos, relaciones, objetos, procesos o lo que fuera de la formación geográfica de referencia.

El segundo aspecto es identificar y caracterizar los vórtices de organización más relevantes que determinan los nexos y contradicciones dialécticas de las formaciones geográficas y caracterizar la combinación que se involucra en la definición de la geograficidad e historicidad de la formación. Este momento de análisis está estrechamente relacionado con las diferentes formaciones territoriales que desarrollamos a continuación.

El tercer momento toca a la cuestión de los límites y fronteras de las formaciones geográficas, temas que son importantes en todos los entes de la realidad, pero que cobran particular intensidad para encarar la individualización y caracterización de las formaciones geográficas debido a sus cualidades no figurativas como las cosas materiales. Hay entes que son materiales y no son figurables.

Sobre el tema no hay protocolos formales universales. Los límites y fronteras, aunque puedan asociarse con mayor o menor artificialidad a ciertas materializaciones, ríos, cordones montañosos, amojonamientos de límites, etc, no tienen existencia objetiva. Los límites y fronteras son el resultado de campos (Bourdieu, 1966, 1988) constituidos por todos los factores objetivos y subjetivos de las formaciones geográficas.

Las formaciones geográficas reales, concretas, son la unidad de muchas, infinitas mediaciones y determinaciones. Por tal motivo no son factibles de geometrización cartográfica, aun cuando la cartografía es imprescindible para ubicar sitios y posiciones en la superficie de la Tierra. Cada formación geográfica condensa en su interioridad, la exterioridad del resto de formaciones geográficas de la superficie de la Tierra, de la ecúmene. Lo interior y exterior constituyen dos rostros de lo mismo. Una vez más: dibujar y circunscribir cartográficamente las formaciones geográficas es una tarea imposible en tanto cada una, en términos dialécticos, es la totalidad de la que forma parte. En esta perspectiva la única solución práctica consiste 
considerar a las formaciones geográficas como campos de convergencia de la totalidad de la que forman parte a partir de los vórtices de interés que determinan las necesidades que sustentan su individualización. El procedimiento involucra atender privilegiadamente los procesos de territorialización que operan en relación a los vórtices de intereses que estructuran el campo de la formación geográfica. El proceso implica identificar en primera instancia la formación territorial que opera dentro del campo, lo cual nos lleva a analizar a continuación la cuestión territorial.

\section{Territorios, territorializaciones, multiterritorialidades y formaciones territoriales}

En el Cuadro $N^{\circ} 2$ hemos introducido las expresiones formaciones territoriales naturales, formaciones territoriales económicas, formaciones territoriales políticas, formaciones territoriales estatales y formaciones territoriales simbólicas. Cada una de ellas está asociada a una instancia específica de la formación geográfica.

Constatamos, en general, la ausencia de las expresiones en la literatura que hemos consultado, aun cuando en pocos casos hay abordajes connotativos ${ }^{20}$.

En el cuadro falta el término que denota la combinación de todas las formas de territorialización. A tal efecto proponemos la expresión formación territorial para denotar la totalidad de formaciones territoriales presentes en las formaciones geográficas que operan para ensamblar y materializar en la superficie de la tierra, en la geografía real, el conjunto de instancias analíticas de las formaciones geográficas.

La cuestión territorial, esencial para dialectizar la geografía, involucra retomar la larga historia de las nociones políticas y geopolíticas de territorio y territorialización que se inician con la formación del Imperio Romano, y revisitar los desarrollos más recientes propuestos, entre muchos, por Zamorano (2001) y Haesbaert $(2004,2005)$.

Sobre los conceptos básicos, territorio y territorialización, hay abundante literatura. Haremos referencia solo a algunas cuestiones que consideramos importantes que marcan algunas diferencias con todos los autores y, en el caso de la noción de multiterritorialidad, con los mencionados Zamorano y Haesbaert. En primer lugar, resaltamos que territorialidad es un atributo relacional asociado a los nexos funcionales y los nexos contradictorios de todas las cosas que, directa o indirectamente, comparten la misma totalidad. La territorialidad está implicada necesariamente en las cualidades mediadoras y determinantes de todas las cosas y procesos, denotando el poder inherente a las formas de relacionamiento. Si no hubiera poder de mediación y determinación, los nexos serían innecesarios y, por 
consiguiente, obligaría a diferenciar en las formaciones geográficas, entidades que, estando dentro de las formaciones, tienen una existencia absolutamente independiente, con lo cual serían innecesarias a los procesos de estructuración asociados da los modos de producción y reproducción.

Por consiguiente, es pertinente reconocer que las territorializaciones y los territorios resultantes son inherentes a la dialéctica de la naturaleza y la cultura y entre los momentos naturales y los momentos culturales de las formaciones geográficas. Son, en definitiva, atributos derivados de las capacidades organizativas de todos los entes en relación a los entes de los cuales forman parte. El punto de vista es, indudablemente, demasiado innovador y, al mismo tiempo, provocador. Marca una notable diferencia con las conceptualizaciones corrientes, que asocian ambos términos a la dialéctica entre las formaciones sociales y la geografía real, mediados por los actores individuales y colectivos.

Otro aspecto diferenciador radica en nuestra propuesta de formación territorial, con la cual denotamos la totalidad de territorios y territorializaciones que existen y operan de manera, directa o indirectamente, interdependientes, combinadas $\mathrm{y}$, a menudo, contradictorias, desde adentro y desde afuera, de las demarcaciones de las formaciones territoriales que se abordan. En términos dialécticos, recordemos, que el establecimiento de los límites son decisiones artificiales.

La noción de formación territorial incluye, en cierto modo, la noción de multiterritorialidad de Zamorano y Haesbaert. La multiterritorialidad denota un mecanismo de articulación entre las múltiples territorializaciones de las formaciones geográficas. La noción de multiterritorialidad, tal como la proponen, denota la necesaria articulación territorial, directa o indirecta, de todos los agentes y agencias, naturales y culturales. Asumiendo el carácter dialéctico de las formaciones geográficas, es una hipótesis poco probable la existencia de territorios y territorializaciones desvinculadas del resto. El arraigo geográfico común necesariamente entrevera a todas las territorializaciones, aun cuando corresponden a procesos de construcción de identidad y pertenencia. Las identidades y pertenencias simbólicas y prácticas son construcciones que presuponen operar en campos de identidades y pertenencias en las que convergen necesariamente actores que disputan la apropiación de los campos (Bourdieu, 1966, 1988).

La cuestión territorial obliga a revisitar las nociones de espacio vital y sentido del espacio introducidas por F. Ratzel al desarrollar la geografía y geopolítica de los estados, y a proponer, atento a las consideraciones efectuadas precedentemente, dos cambios significativos superadores, sin desestimar para ciertos propósitos, los alcances de su propuesta. La superación consiste en resignificar ambas expresiones mediante el cruce de los aportes de A. Gramsci con los procesos de territorialización. En efecto, 
proponemos la noción de territorio orgánico y sentido territorial orgánico para ampliar los alcances territoriales implicados en las nociones de espacio vital y sentido del espacio respectivamente.

Territorio orgánico denota el resultado de territorializaciones que son indispensables para la producción y reproducción de los sujetoobjetos y los objetosujetos. Sentido territorial orgánico denota la geograficidad implicada en las territorializaciones, es decir, el sentido territorial asociado a la reproducción de los agentes y agencias, reproducción que a su vez direcciona lo producción de territorios. La producción de territorios está o debería estar siempre subordinada a la reproducción orgánica ampliada de los agentes y agencias.

Antes de cerrar este apartado es necesario resaltar que la geografía no es una hoja en blanco que posibilite cualquier forma de territorialización. Los procesos de territorialización requieren ambientes geográficos que los posibiliten, lo cual implica que deben existir condiciones de la primera naturaleza y la segunda naturaleza, conjuntamente con condiciones culturales. Dicho de otro modo, las territorializaciones requieren la participación y desarrollo de gran parte de los aspectos que son propios de las instancias de las formaciones geográficas en las cuales se despliegan. A título de ejemplo, la expansión territorial sojero y minero que, para algunos son claros ejemplos de extractivismo, no son posibles si las geografías carecen de suelos y recursos mineros, de tecnologías apropiadas y formas jurídicas y técnicas de propiedad y apropiación para llevar adelante el corrimiento de las fronteras agrarias y mineras. Otro ejemplo lo constituyen las expansiones territoriales urbanas. Ningún proceso de territorialización es posible en las geografías, si las geografías no tienen o no desarrollan previamente las condiciones ambientales indispensables para la producción y reproducción de los agentes y agencias.

Finalizamos aquí las consideraciones sobre la cuestión territorial de la geografía en general y las formaciones geográficas, lo cual no significa que lo expuesto agota la diversidad de aspectos involucrados. Solo hemos procurado resaltar la importancia que tienen los procesos de territorialización como instancia de articulación y puesta en valor (usos) de las formaciones sociales y las formaciones naturales.

Los temas, sujetos a revisiones y ampliaciones, fueron desarrollados con el objetivo de presentar la importancia del concepto de formación geográfica para complementar, en clave dialéctica y totalizadora, la amplia difusión del espacio geográfico como objeto de la geografía. Creemos, sin embargo, que la exposición es suficientemente clara para contribuir 
a deconstruir y superar la noción de espacio geográfico como categoría estructuradora del quehacer disciplinario.

Creemos que la importancia del método dialéctico geográfico e histórico ha sido también suficientemente resaltada. Estamos convencidos que es imprescindible reemplazar el soft mental de la lógica formal con el soft dialéctico. Sin este cambio sustantivo, es imposible avanzar incesante y superadoramente en el desarrollo crítico del campo disciplinario y, a la vez, enfrentar con propuestas propositivas los desafíos que plantean a la disciplina los siempre renovados requerimientos sociales de saberes y habilidades geográficas, asumiendo que no hay un monopolio natural de la disciplina sobre la diversidad de su vasto campo temático. Las necesidades sociales no esperan el despertar de los geógrafos. Seguramente otros campos disciplinarios, tal como se evidencia en el último siglo de la historia de las ciencias, territorializaran el temario, tanto en los ámbitos expertos (Giddens, 1995) de las aplicaciones, como en el ámbito educativo.

\section{Referenicias biblográficas}

Abbagnano, Nicola, (1971), Cuatro conceptos de dialéctica, págs.11/24. Disponible en:https://pdfslide.tips/documents/abbagnano-nicolas-la-evolucion-de-la-dialectica1958.html

Aglietta, Michel, (1976), Regulación y crisis del capitalismo, Ed. Siglo XXI, México.

Apel, Karl-Otto (1985), La Transformación de la Filosofia, T.I-Análisis del lenguaje, simiótica y hermeneutica. T.II-El apriori de la comunidad de la comunicación, Ed. Taurus, España.

Aricó, José (1985), Introducción general a la Crítica de la Economía Política/1957 y otros textos de Karl Marx, Cuadernos de Pasado y Presente $N^{\circ} 1$, ed. Siglo XXI, 17a. ed, México.

Assadourian, Carlos Sempat, 1973, Sobre un elemento de la economía colonial: Producción y circulación de mercancías en el interior de un conjunto regional, en EURE, Vol. III, pp. 135-181.

Berger, Peter L. y Luckmann, Thomas, 1967(1968), La construcción social de la realidad, Amorrortu Editores, Bs. Aires, 7a. reimpresión, 1984 [1a. ed. 1968].
Bobbio, Norberto, 1958(1971), La dialéctica en Marx, en Abbagnano, Nicola y otros, 1971, págs. 253/275.

Bobbio, Norberto, 1958 (1964), Notas sobre la dialéctica en Gramsci, en La rosa blindada, Año 1, No. 2, noviembre de 1964 , Buenos Aires, pp. 3-8.

Borja, Jordi, (1983), Los actores sociales en la construcción de la ciudad, Ciudad y Territorio, $\mathrm{N}^{\circ} 3 / 4$.

Bottomore, Tom y otros, 1983(1984), Diccionario del pensamiento marxista, Ed. Tecnos, Madrid.

Bourdieu, Pierre, (1966), Campo intelectual y proyecto creador, en Pouillon y otros.

Bourdieu, Pierre, 1987 (1988), Cosas Dichas, Ed. Gedisa, Argentina.

Capel, Horacio, (1981), Filosofía y ciencia en la geografía contemporánea. Una introducción a la geografía. Editorial Barcanova S.A., España.

Castells, Manuel, (1972), La cuestión urbana, Ed. Siglo XXI, España.

Di Cione, Vicente, (1974), El Departamento Minas - Nor-oeste de la Provincia de Neu- 
quén-Aspectos teórico-metodológicos, en Di Cione, Vicente, El Nor-oste de la Provincia de Neuquén. Ensayo de interpretación geográfica, UBA-FFyL.

Di Cione, Vicente, 1984 (1997), Apuntes para una definición de la Geografía, en M. Santos y V. Di Cione, 1997, pp. 33-78.

Di Cione, Vicente, (1986), Esbozo de Teoría y Métodos de la Geografía, Materiales de la asignatura teoría y métodos II, Departamento de Geografía, FFyL-UBA.

Di Cione, Vicente, (1997), Espacio/Tiempo, Naturaleza/Cultura y Geografía/Historia en Hegel, en M. Santos y V. Di Cione, 1997, pp. 79-100.

Di Cione, Vicente, 1985 (1992), Autoconstrucción de viviendas, vida cotidiana y urbanización en Argentina. Consideraciones a partir de la urbanización del Gran Buenos Aires, UNCPBA, FCH, CUADERNOS, Serie Aportes, Tandil.

Di Cione, Vicente, (1999), Realidades, geografías y geógrafos. Tradición y renovación disciplinaria en el alba del tercer milenio, Geobaires, Cuadernos de Geografía.

Di Cione, Vicente, (2000), Dialéctica y pensamiento complejo. Diferencias y convergencias, Cuadernos de Geografía, Geobaires.

Di Cione, V. (2004), Universos, niveles, campos y escalas de investigación, en Darío G. Barriera y Diego P. Roldán (compiladores), Territorios, espacios, sociedades: agenda de problemas y tendencias de análisis, Editorial de la Universidad Nacional de Rosario, Argentina.

Di Cione, V., (2003), Diálogos y monólogos entre/de las ciencias naturales y sociales y la geografía física, la geografía social y las ciencias sociales, en Apuntes de geografía y ciencias Sociales.

Di Cione, Vicente, (1998), Hacer, Participar, Investigar. Notas sobre teoría, metodología de la investigación y prácticas sociales, Cuadernos de PROSIPO, UBA-FFyL.

Di Cione, Vicente, (2008), Megaminería, multiterritorialidades y ciudadanía. Las políticas de escala y las escalas de la política de la minería en gran escala en Argentina, Encuentro Políticas del territorio y territorios en construcción. Minería a gran escala y nuevos trazados de la Argentina, la Universidad Nacional de Córdoba, Facultad de Filosofía y Humanidades, 9 de setiembre de 2008.

Estrabón, (1991). Geografía. Libros I y II, Editorial Gredos.

Ferrater Mora, José, (1969), Diccionario de Filosofía, Editorial Sudamericana, Buenos Aires, reimpresión de la 5 a. ed.

Gómez Mendoza, Josefina y otros, (1982) El pensamiento geográfico, Ed. Alianza, España.

Haesbaert, R., (2004), O mito da desterritorialização: do fim dos territórios à multiterritorialidade, Bertrand, Rio de Janeiro.

Haesbaert, R., (2005), Da desterritorialização à multiterritorialidade, en Annais do $X$ Encontro de Geógrafos da America Latina, USP, San Pablo.

Harvey, David, (1983), Geografía, en Bottomore, Tom, Diccionario del pensamiento marxista, Tecnos, España.

Harvey, David, 1989 (1998), La condición de la posmodernidad. Investigación sobre los orígenes del cambio cultural, Amorrortu Editores, Buenos Aires.

Hegel, G.W.F, 1812-1816 (1982), Ciencia de la Lógica (tomos I y II) Ediciones Solar Argentina. [Título original: Wissenschaftderlogik Traducido por: Augusta y Rodolfo Mondolfo Primera edición castellana.

Hegel, G.W.F., 1807(1973), Fenomenología del Espíritu, Fondo de Cultura Económica, México, 1973 (2a reimpresión). [Título original: Phanomenologie des geistes. Primera edición castellana 1966].

Hegel, Guillermo Federico, 1817 (1944), Enciclopedia de las ciencias filosóficas, Ediciones Libertad, Biblioteca Clásica de Obras Maestras, Bs. As. 1944. [Traducción del Alemán por E. Ovejero y Maury].

Hegel, Guillermo Federico, 1832/87 (1986), Lecciones sobre la filosofía de la historia universal, Alianza Editorial, Madrid. 
Kosik, Karel, (1963), Dialéctica de lo concreto, Ed. Grijalbo, México.

Labica, George, (1973), Cuatro observaciones sobre los Conceptos de modo de Producción de la Sociedad, en Luporini, Cesare y Sereni, Emilio, 1973 pags. 206/217 y 247/248.

Laclau, Ernesto, (1969), Modos de producción, sistemas económicos y población excedente. Aproximación histórica a los casos argentinos y chilenos, en Revista Latinoaméricana de Sociología, No. 2, 1969, pp. 276-312.

Lagarec, Daniel (1997), Por una geografía física revisitada, en Di Cione, Geografía por venir. Cuestiones, Opiniones, Debates, Coop. EditoraUniversitaria (CEU), Buenos Aires [Versiónoriginal: Pour une géographie phisique revisitée, Cahiers de Géographie du Quebec, La géographie : quel avenir?, № 108, 1995, pp.509/517].

Latour, Bruno, 2008, Re-ensamblar lo social. Una introducción a la teoría del actorred, Buenos Aires, Manantial.

Lefebvre, Henri, 1970 (1983), La revolución urbana, ed. Alianza, Madrid.

Lefebvre, Henri, 1947 (1973), Lógica Formal/Lógica Dialéctica, Ed. Siglo XXI, 2a. ed., México [1a. ed. Toulouse, 1946/47; 2a. ed. de Editions Anthropos, París, 1969)].

Lefebvre, Henri, (2013), La producción del espacio, ed. Capitán Swing, Madrid.

Luporini, Cesare, Sereni,Emilio y otros, 1966(1973), El concepto de Formación económico-social, ed. Siglo XXI, Cuadernos de Pasado y Presente №39, Córdoba Margulis, Mario, (2005), Ideología, fetichismo de la mercancía y reificación, en Geobaires. Cuaderno de Geografía, Buenos Aires.

Marx, K.,(1985) Introducción a la crítica de la economía política de 1857, en Aricó.

Marx, K.,(1985) Prólogo al Capital, en Aricó, 1985.

Massey Doreen (2000) O sentido global de lugar. Brasil. Campinas. Papirus.

Milner, Jean-Claude, (2007), La política de las cosas, Miguel Gómez ediciones, España.
Peet, Richard, (1978), Materialism, social formation and socio-spatial relations: an essay in marxist geography, en Cahiers de Geographie du Quebec, Vol.22, №56, Septiembre de 1978.

Piaget,Jean y otros, (1971), La epistemología del espacio, Ed.Ateneo, Buenos Aires.

Piaget Jean y García, Rolando, (1982), Psicogénesis e Historia de la Ciencia, ed. Siglo XXI, México.

Portelli, Hugues, 1972 (1973), Gramsci y el Bloque Histórico, Ed. Siglo XXI, Bs.As. 1973 [1a. ed. francesa, Paris, 1972].

Rofman, Alejandro B. y Romero, Luis A., (1973), Sistema socioeconómico y estructura regional en Argentina, ed. Amorrortu, Bs. Aires.

Sack, R.D., (1986), Human Territoriality: Its Theory and History, University Press, Cambridge, Cambridge.

Santos, Douglas, (2002), Areinvenção do espaço. Diálogos em torno da construção do significado de uma categoría, Editora UNESP, San Pablo.

Santos, Milton y Di Cione, Vicente, (1997), Geografía por venir. Cuestiones espistemológicas, Cooperativa Editora Universitaria. Textos de Geografía, Buenos Aires.

Santos, Milton, (1984), La geografía a fines del siglo XX: nuevas funciones de una disciplina amenazada, en Revista Internacional de Ciencias Sociales, Epistemología de la Ciencias Sociales, 102, Unesco, Vol. XXXVI, № 41984.

Santos, Milton, 2000, La naturaleza del espacio. Técnica y tiempo. Razón y emoción, Ariel Geografía, Barcelona.

Sormani, Horacio A., (1977), Formación Social y Formación Espacial: hacia una dialéctica de los asentamientos humanos, en Estudios Sociales Centroamericanos. Año VI, No. 17, mayo-agosto 1977 (pp.147-173).

Sunkel, Osvaldo y Paz, Pedro, (1970), El subdesarrollo latinoamericano y la teoría del desarrollo, ed. Siglo XXI, México. 
Touraine, Alain, (1975), Las clases sociales, en Benitez Zenteno (Coordinador), 1975, Las clases sociales en América Latina, ed. Siglo XXI, México, p. 3-71.

Varsavsky, Oscar, (1969), Ciencia, Política y Cientificismo, CEAL, Bs. Aires.

Verón, Eliseo, (1987), La semiosis social. Fragmentos de una teoría de la discursividad, ed. Gedisa, Argentina.

Zambrano, Carlos, (2001), Territorios plurales, cambios sociopolíticos y gobernabilidad cultural, en Boletín Goiano de Geografía, 21, pp. 9-49.

\section{Notas}

1 Profesor titular regular de Teoría y métodos de la Geografía (Departamento de Geografía, FFyL-UBA, 1985 a 2008). Director de Geografías del Sur. Consultor independiente. Consultas y comentarios: vdicione@yahoo.com

2 Debemos a muchos geógrafos la generalización contemporánea de espacio geográfico. En Latinoamérica es indiscutible el esfuerzo conceptual llevado a cabo por Milton Santos, al definirlo como un sistema de objetos y un sistema de acciones. Su propuesta presenta varias dificultades. La primera consiste en omitir que los objetos y acciones concretas, empíricas, que aborda la geografía son simultáneamente espaciales y temporales. En varios textos el mismo Santos resalta la importancia del tiempo para comprender las transformaciones espaciales. En consecuencia, el objeto disciplinario debiera definírselo como espacio-tiempo geográfico. En segundo lugar, dado que la realidad, en general, puede considerarse un sistema de objetos y un sistema de acciones, faltaría precisar cuando ambos sistemas pueden considerarse específicamente geográficos (Santos, 1978, 1984, 2000).

3 En La producción del espacio, Lefebvre menciona en muchas oportunidades superficie terrestre, suelo, territorio y, fiel al pensamiento de Hegel, naturaleza, a los fines de connotar la materialidad de la noción de espacio y distinguirla del espacio abstracto. El espacio abstracto sólo puede aprehenderse abstractamente mediante un pensamiento que separa la lógica de la dialéctica, que reduce las contradicciones a la coherencia y que mezcla los residuos de esa reducción (por ejemplo, la lógica y la práctica social). El espacio abstracto, considerado como instrumento (y no sólo como apariencia social) es en principio el lugar de la naturaleza, el útil que quiere dominarla y aspira en última instancia a su destrucción. Este mismo espacio corresponde a la ampliación de la práctica (social) que engendra redes cada vez más vastas y densas por la superficie terrestre, y por debajo y por encima de ella. Pero se corresponde también con el trabajo abstracto (Marx designaba así al trabajo en general, el trabajo social medio, productor del valor de cambio, de la forma general de la mercancía) (Lefebvre, 2013, pág. 344).

4 La imposibilidad, veremos, es el resultado de la dialéctica todo-parte. La parte es la totalidad puesta en la parte. Las divisiones son siempre artilugios artificiales, resultantes de criterios puramente ostensivos, arbitrarios, y de criterios regulados mediante protocolos teóricos y metodológicos.

5 Tornar geométrica la representación [de la realidad], vale decir dibujar los fenómenos y ordenar en serie los acontecimientos decisivos de una experiencia, he ahí la primera tarea en la que se funda el espíritu científico. En efecto, es de este modo cómo se llega a la cantidad representada, a mitad de camino entre lo concreto y lo abstracto, en una zona intermedia en la que el espíritu pretende conciliar las matemáticas y la experiencia, las leyes y los hechos. Esta tarea de geometrización que a menudo pareció lograrse... termina siempre por revelarse insuficiente. Tarde o temprano..., estamos obligados a comprobar que esta primera representación geométri$\mathrm{ca}$, fundada sobre un realismo ingenuo 
de las propiedades espaciales, implica conveniencias más ocultas, leyes topológicas menos firmemente solidarias con las relaciones métricas inmediatamente aparentes, en una palabra: vínculos esenciales más profundos que los vínculos de las representaciones geométricas familiares. Poco a poco se advierte la necesidad de trabajar debajo del espacio, por así decir, en el nivel de las relaciones esenciales que sostienen los fenómenos y el espacio. El pensamiento científico es entonces arrastrado hacia construcciones más metafóricas que reales, hacia espacios de configuración de los que el espacio sensible, en definitiva, no es sino un mísero ejemplo (Bachelard, "Palabras preliminares», en La formación del espíritu científico, 1972).

6 Recordemos que la geografía universitaria tuvo su origen a partir de la sección de geografía de las carreras de historia de la UBA y la UNCuyo (Mendoza) hacia fines de la década de los 40 del siglo pasado. También fue precedida a partir del siglo XIX como necesario complemento de la economía política.

7 La importancia del lugar (topos) lo destaca Henri Lefebvre al comienzo de su Lógica Formal, Lógica Dialéctica (1969), parafraseando el primer versículo del Evangelio de Juan, a modo de preámbulo, escribe: En el principio fue el Topos. Aunque no utiliza la expresión, para Lefebvre los lugares son de la superficie de la Tierra, considerada como lugar de lugares, es decir, como origen de todas las formas de intuición, percepción y representación del hombre, del mundo del hombre y de la humanidad. En La producción del espacio (1986), considera que la tierra es el origen de los diferentes momentos de producción del espacio. La revisión histórica de los saberes y prácticas geográficas hasta el presente, dejan entrever, con menor o mayor explicitación, que la idea de geografía de Heródoto, Estrabón, Eratóstenes (creador del término geografía), Ptolomeo y muchos otros sigue vigente, aun cuando las ciencias, en general, y la geografía, en particular, desarrollaron una enorme cantidad de recursos tecnológicos, entre ellos la expansión conceptual intra, multi y transdisciplinaria de conceptos y teorías. Los griegos utilizaban el término ecúmene (oikouménē) para denotar la superficie terrestre habitada y anecúmene para la tierra no habitada o solo habitada circunstancialmente. También utilizaban el término spodium para indicar el suelo dónde podían caminar personas y animales. Spodium fue traducido al latín como spatium, término que dio origen a la noción de espacio. Para los romanos el spatium era sencillamente el suelo en el cual podían caminar o asentar actividades. Los términos territorio y región denotaban configuraciones políticas de suelo habitado, habitable y de posible dominación. Tierra aparece 69 veces y suelo 46 veces.

8 Aleph, sugerido por el cuento de Borges: un lugar desde el cual es posible primariamente ordenar las experiencias de la realidad geográfica y, a la vez, orientar el análisis y síntesis de la diversidad de formas geográficas de la superficie terrestre. El Aleph es a la vez un mapa conceptual básico y una brújula que posibilita el trazado de itinerarios entre los diferentes momentos conceptuales que se explicitan, los que, veremos, son congruentes con la diversidad insoslayables de requerimientos de desarrollo intra, inter y transobjetales $y$, atendiendo la institucionalización del conocimiento, de desarrollo y articulación inter y transdisciplinarios.

9 Considerando la generalización de usos ostensivos de los términos en la disciplina, sería importante desarrollar las diferentes propuestas, lo cual sobrepasa las posibilidades de este texto de presentación. Recomendamos particularmente a Bloch (1962), Berger y Luckmann (1967), Verón (1987) y Apel (1985).

10 Todo lo racionalmente conocido son formaciones con dos significados: como proceso de formación y como resultado o producto de la formación. La distinción es importante tenerla presente en todos los procesos reales e ideales (con- 
ceptuales). La formación determina al producto y el producto a lograr al proceso de formación.

11 El cono invertido es, en rigor, una sucesión de capas (círculos espiralados), de las cuales solo se ha dibujado la resultante de las capas correspondientes a los momentos previos que se indican debajo de los sectores de la historicidad y geograficidad. La noción de espacio y lugar son anteriores a la noción de geografía y muy anterior al de geograficidad. Otro tanto con los momentos previos temporales de formación de las nociones de historia e historicidad. La noción de naturaleza es también muy posterior a la noción de lugar. Otro tanto con la noción de cultura, la cual supone romper que el estado de naturaleza de los lugares y la naturalización de la vida social, mediante la producción de sucesivas fases de segunda naturaleza. Faltan en la figura representar las fases de la extensa apertura analítica de las ciencias de la naturaleza y las ciencias de la cultura, resultantes de procesos formativos de distinciones analíticas y la paulatina institucionalización de la división del trabajo intelectual. Tales desarrollos están representados por los sectores de la capa explicitada. La geografía tuvo desarrollos en todos los cuadrantes: geografía física, geología, geomorfología, climatología, etc., en el cuadrante inferior izquierdo. La geografía cultural y las restantes geografías sociales repartidas en los cuadrantes de la cultura. La fuerte identidad entre historia social y geografía social fundacionales, recorre los cuadrantes del hemisferio de la cultura. La historia de la tierra, en términos geológicos y de la geografía física se ubican en los cuadrantes del hemisferio de la naturaleza.

12 El Aleph opera como un macro marco teórico y metodológico general en perspectiva nomotética. Todos los sustantivos pueden considerarse, en general, como teorías nomotéticas. Al igual que con el uso de los sustantivos, el pasaje a la instancia empírica implica el inicio de un proceso de construcción especí- fico del cono invertido. La praxis concreta involucra siempre a la dialéctica entre formaciones nomotéticas ideales y formaciones ideográficas concretas. El proceso de conjunto se lo reconoce como círculo metodológico concretoabstracto-concreto. El primer concreto es el inmediato y el último el resultado síntesis de los nuevos descubrimientos abstractos o analíticos.

13 La praxis es el puente que posibilita identificar primariamente los momentos analíticos espacio, tiempo, naturaleza y cultura. Estos términos-momentos tienen una larga historia. Asumiendo la coincidencia entre el proceso histórico de la distinción y el proceso sicogenético (Piaget, 1971; Piaget-García, 1982), los vectores espaciales y temporales, a medida que ascienden, distinguen otras propiedades de la espacialidad y temporalidad: formas geográficas del espacio y etapas de la temporalidad. Por tal motivo las nociones inmediatas de espacio y tiempo se encuentra más próxima al origen del inferior del cono.

14 En el comienzo del proceso (vértice inferior del cono), la praxis identifica de manera solidaria al espacio y al tiempo, como formas a priori del entendimiento para Kant, y como formas inmediatas de la materia o, en rigor, de la exterioridad de los conceptos, para Hegel. Dicho de otro modo, la materialidad es la más inmediata manifestación de la objetividad de los conceptos y de las teorías construidas con conceptos. Conceptualizar es la función principal del proceso de pensamiento, igualmente dialéctico.

15 Dada su importancia en la geografía, en especial la deconstrucción del concepto de espacio geográfico, la articulación espacio-tiempo amerita una breve digresión. El tiempo y la temporalidad de la realidad están indisolublemente ligados a los cambios cíclicos o renovadores del espacio y la espacialidad de la realidad. Sin cambios espaciales de la realidad, sin el movimiento de la realidad, no es posible percibir y construir la noción de tiempo. El tiempo resulta ser sencilla- 
mente el movimiento o transformación de los estados de naturaleza de la realidad. La dialéctica espacio-tiempo subvierte la posibilidad de considerar objeto de la geografía al espacio geográfico y fuerza a la razón a reemplazarlo por alguna noción integradora más congruente con la materialidad espacio-temporal del universo fenoménico que abarca.

16 La forma de las sillas determina la forma de sentarse. La forma de la ochava de una esquina obliga a transitarla de determinadas maneras. Las formas de las veredas determinan el menor o mayor cuidado para caminar. Las características de los lugares, en general, condicionan, mediatizan y determinan, dialécticamente, las formas posibles de territorializaciones u ocupaciones de cosas y personas.

17 Todas las cosas, interpretando a Hegel, son a la vez resultado de procesos de organización, de formación y, a la vez, de ser organizadas y formadas por los ambientes que comparte con otras cosas. La cualidad fue tematizada recientemente por C. Latour (2008).

18 En relación al Cuadro $N^{\circ} 2$, salvo en los casos necesarios, por cuestiones de extensión determinadas por la publicación, omito los significados de los términos tales como objetos de trabajo, medios de trabajo, fuerza de trabajo, fuerzas de producción, relaciones de producción. A tal efecto puede consultarse Di Cione (1986) y otros textos citados en la bibliografía. Me detengo solo en explicitar algunos aspectos y categorías.

19 El término reproducción es utilizado en demografía para denotar el crecimiento de las poblaciones. Aplicado a la dinámica de la formación geográfica, se retoma el significado de reproducción utilizado en la economía política para indicar el sentido de la producción: reproducir la sostenibilidad y fortalecimiento de las relaciones estructurales que determinan el modo de producción en el cual la producción se lleva a cabo. La producción capitalista no se orienta a la producción de mercancías si la producción y los momentos asociados, consumo, distribución y circulación, no garantizan su existencia y la acumulación en sucesivos ciclos de realización de la internalización de plusvalor social. Producción y reproducción son dos momentos indisolublemente ligados. La producción determina a la reproducción y la reproducción a la producción.

20 Llama la atención que los términos territorio, territorialización y afines no son entradas en los diccionarios de ciencias sociales y políticas. Es llamativo, teniendo en cuenta la importancia en la teoría social crítica, que los términos son inexistentes en el Diccionario del pensamiento marxista de Bottomore, Miliband y otros (1984). También está ausente en A. Giddens, emblemático referente de la teoría social de la estructuración (Giddens, 1995). 